\title{
7,8,15,16-Tetraazaterrylene. It's as Simple as One, Two, Three
}<smiles>O=C1CC(=O)c2cccc3cccc1c23</smiles>

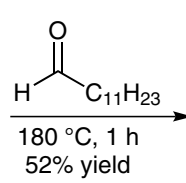<smiles>O=C1c2cccc3cccc(c23)C(=O)C1C1C(=O)c2cccc3cccc(c23)C1=O</smiles>

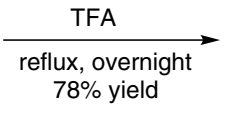

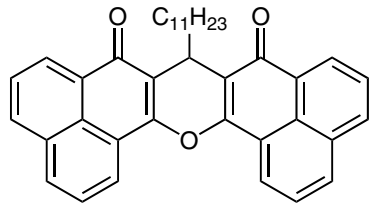

3

\section{Category}

Synthesis of

Materials and

Unnatural Products

\section{Key words}

tetraazaterrylene

rylenes

n-type materials

\section{SYNFACTring}

3

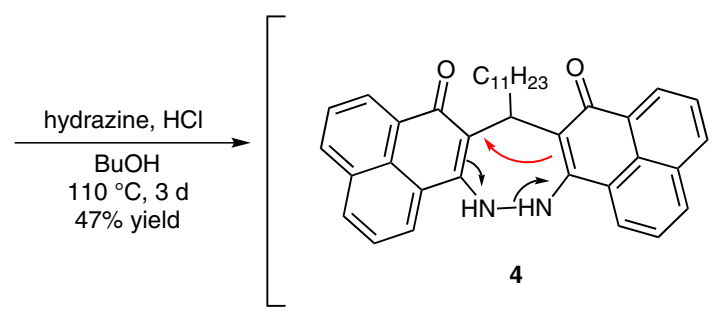<smiles>N=C1c2cccc3cccc(c23)C(=O)C1C(CCCN)(CCNN)C1C(=O)c2cccc3cccc(c23)C1=NN</smiles>

Significance: Perylene derivatives find applications in organic electronics as electron-transport materials. Now, a facile three-step synthesis of 7,8,15,16-tetraazaterrylene opens the door for higher rylenes which have not been studied as extensively. Knoevenagel condensation of phenalene-1,3-dione (1) with lauric aldehyde is followed by a Michael addition of a second molecule of $\mathbf{1}$ to give $\mathbf{2}$. This is heated in neat trifluoroacetic acid effecting the cyclodehydration to $\mathbf{3}$.
Comment: The last step is a domino reaction with hydrazine that produces tetraazaterrylene $\mathbf{6}$ while the solubilizing alkyl chain is expelled as a hydrazone. A mechanism for the domino reaction has been proposed by Tu (Org. Biomol. Chem. 2009, $7,1171)$ and involves formation of diazepine 4 which would undergo a 3,3-sigmatropic rearrangement to form the transannular $\mathrm{C}-\mathrm{C}$ bond (red). The use of a long-chain aliphatic aldehyde is deliberate - it ensures solubility of $\mathbf{2}$ and $\mathbf{3}$ and favors the formation of the tetraaza-product 6 . 